\title{
MODEL PEMBELAJARAN BERBASIS MASALAH (PBL) TERHADAP LITERASI SAINS SISWA KELAS V SEKOLAH DASAR
}

\author{
${ }^{1)}$ Ummu Aiman \& ${ }^{2)}$ Rizqy Amelia Ramadhaniyah Ahmad \\ ${ }^{1,2)}$ Program Studi Pendidikan Guru Sekolah Dasar \\ ${ }^{1,2)}$ Universitas Muhammadiyah Kupang \\ E-mail: ${ }^{1)}$ aimanpgsdumk93@gmail.com ${ }^{2)}$ rizqy.ahmad92@gmail.com
}

\begin{abstract}
Abstrak
Tujuan utama penelitian ini untuk mengetahui peningkatan kemampuan literasi sains siswa yang belajarkan model $P B L$ dan dibelajarkan metode ekspositori. Penelitian eksperimen semu (quasi experiment) dan desaian post-test only control group design. Data literasi sains diperoleh melalui tes. Kemudian dianalisis dengan menggunakan teknik statistik deskriptif

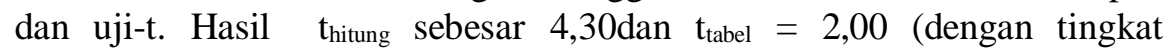
signifikasi 5\%). Berarti $t_{\text {hitung }}>\mathrm{t}_{\text {tabel, }}$ maka simpulkan bahwa adanya perbedaan yang signifikan literasi sains siswa yang dibelajarkan dengan model $P B L$ dan metode ekspositori. Dari rerata skor literasi sains, berada pada kategori sangat tinggi dengan Mean 23,51 sedangkan kelompok kontrol berada pada kateogri sedang dengan hasil Mean 15,75. Jadi, kesimpulannya bahwa model $P B L$ meningkatkan literasi sains siswa kelas V SD Muhammadiyah 2 Kota Kupang.
\end{abstract}

Kata kunci:

PBL, Literasi Sains, Sekolah Dasar

\begin{abstract}
The aim of this research is to find out the improvement of students' scientific literacy skills who learn PBL models and expository methods. Quasi-experimental research and a post-test only control group design design. Data on scientific literacy was obtained through tests. Then analyzed using descriptive statistical techniques and t-test. The result of tcount is 4.30 and ttable $=2.00$ (with a significance level of 5\%). Means tcount> ttable, then it was concluded that there are significant differences in scientific literacy of students who are taught with PBL models and expository methods. From the average scientific literacy score, it is in the very high category with a Mean of 23.51 while the control group is in the medium category with a mean of 15.75 . Therefore, the conclusion is that the PBL model increases the scientific literacy of fifth grade students of SD Muhammadiyah 2 Kupang.
\end{abstract}

Keywords: PBL, scientific literacy, elementary school

\section{PENDAHULUAN}

Sekolah dasar merupakan tempat formal pertama kali siswa mendapatkan pembelajaran sains. Pengalaman yang didapatkan siswa dalam pembelajaran sains akan menjadi bekal pengetahuan untuk melanjutkan ke jenjang pendidikan yang lebih tinggi. Pendidikan sains disekolah dasar bertujuan untuk mengembangkan pengetahuan terhadap pemahaman konsep sains yang bermanfaat untuk diterapkan dalam kehidupan sehari-hari. Selain itu juga pembelajaran IPA dapat mengembangkan rasa ingin tahu, dan sikap positif terhadap hubungan masyarakat, lingkungan, dan teknologi (Windyariani, 2017).

Tujuan pendidikan sains menunjukkan perlu adanya pengajaran kepada siswa untuk memanfaatkan pengetahuan sains, mengidentifikasi pertanyaan, dan menarik kesimpulan berdasarkan bukti-bukti yang ada dalam rangka memahami serta membuat keputusan sesuai dengan alam dan perubahan dalam kehidupan sehari-hari yang di kenal dengan literasi sains PISA (2018). Literasi sains kini menjadi tuntutan yang harus di kuasai oleh setiap individu 
pada dunia pekerjaan (Zainab dkk, 2017). Siswa yang memiliki keterampilan literasi sains akan menerapkan pengetahuan mereka untuk memecahkan permasalahan baik dalam lingkup pribadi, sosial maupun dalam situasi kehidupannya.(Yuriza dkk, 2018). Hal pertama dalam menerapkan literasi sains harus melihat keterlibatan siswa dalam belajar berdasarkan pengalaman yang dialami dalam kehidupan yang berkaitan dengan pengetahuan siswa didapatkan dari literasi sains (Hidayati, 2018).

Hasil survey PISA 2018 menunjukkan bahwa rata-rata literasi sains untuk Indonesia masih berada di bawah kategori rendah dibandingkan dengan negara- negara lain. Dimana Indonesia masih menduduki peringkat 73 dari 79 negara dengan skor 396 pada bidang literasi sains. Hal tersebut menunjukkan bahwa peserta didik Indonesia masih sangat rendah terhadap sains dan teknologi. Sejalan dengan itu Rahayuni (2014) juga menyatakan bahwa rendahnya literasi sains peserta didik Indonesia disebakan banyak hal, antara lain yaitu kurikulum, pemilihan metode dan model dalam pembelajaran oleh guru, sarana dan prasarana, sumber belajar, dan lain sebagainya. Salah satu faktor yang berkaitan langsung dengan kegiatan pembelajaran siswa dan mempengaruhi rendahnya literasi peserta didik Indonesia adalah pemilihan metode dan model oleh guru.

Berdasarkan hasil observasi yang didapatkan di sekolah dasar Muhammadiyah 2 Kupang, ada beberapa permasalahan yang ditemukan pada pembelajaran IPA terutama berkaitan dengan literasi sains yang masih sangat rendah, hal ini disebabkan karena saat proses pembelajaran dilaksanakan belum adanya partisipasi siswa untuk berperan aktif dalam pembelajaran terutama mengembangkan proses literasi sains, kemudian pembelajaran masih terfokus pada guru (teacher centered) masih kurang melibatkan siswa secara aktif sehingga menyebabkan sebagian besar siswa tidak mampu menghubungkan materi dengan pengetahuan yang dimilikinya serta pemanfaat materi tersebut dalam kehidupan sehari-hari.

Melihat kondisi seperti itu demikian harus adanya inovasi khususnya pembelajaran IPA, agar mempermudah siswa dalam meningkatkan kemampuan bepikir dalam menerapkan konsep-konsep sains sehingga tercapai hasil yang lebih maksimal. Model pembelajaran yang sesuai dalam mengatasi masalah yang terjadi adalah model pembelajaran berbasis masalah. Alasan menggunakan model pembelajaran ini yaitu: (1) melalui model $P B L$, siswa dapat belajar mengingat, menerapkan, dan melakukan kegiatan proses belajar secara mandiri,(2) siswa diberikan perlakuan secara bebas untuk mengimplementasikan pengetahuannya dalam menyelesaikan sebuah masalah. Menurut (Triyana, dkk 2014) menyatakan bahwa $P B L$ merupakan pembaharuan dalam pembelajaran, dikarenakan siswa akan lebih optimal dalam berpikir melalui kerja dalam tim, akan membuat siswa mampu mengasah kemampuan berpikirnya secara berkesinambungan. $P B L$ dilaksanakan pada kegiatan inti dalam pembelajaran yang terdiri dari lima tahap yaitu: 1) memberikan siswa dengan sebuah permasalahan, 2) mengatur siswa untuk belajar, 3) membimbing siswa secara mandiri maupun kelompok, 4) membuat hasil laporan, serta 5) memaparkan hasil laporan (Hartati, 2016). Berdasarkan uraian latar belakang di atas, dapat diungkapkan bahwa model pembelajaran berbasis masalah diduga memberikan pengaruh pada pembelajaran IPA terutama pada literasi sains. Namun besarnya pengaruh tersebut belum pasti diketahui. Oleh karena itu perlu melakukan penelitian tentang "Model pembelajaran berbasis masalah $(P B L)$ terhadap literasi sains siswa kelas V SD Muhammadiyah 2

\section{METODE}

Penelitian ini merupakan penelitian eksperimen semu (quasi eksperimen) yang dilaksanakan di SD Muhammadiyah 2 Kota Kupang dengan jumlah populasi 58 siswa. Dengan menggunakan rancangan "Post Test Only Control Design". Pengambilan sampel penelitian dengan teknik random sampling, Variabel penelitian yaitu variabel bebas model pembelajaran berbasil masalah dan variabel terikat literasi sains. Data dikumpulkan adalah hasil literasi sains peserta didik pada mata pelajara IPA. Pengumpulan data dilakukan dengan 
metode tes dan menggunakan satu jenis alat (instrumen) penelitian yaitu berupa tes pilihan ganda 30 butir soal. Data yang telah diperoleh kemudian dianalisis deskriptif, dengan mencari mean, median, modus, dan standar deviasi. Dengan teknik analisis data yang digunakan varians satu jalur (ANAVA A).

\section{HASIL DAN PEMBAHASAN \\ Hasil}

Data hasil skor berpikir kritis siswa kelas eksperimen berjumlah 29 orang dengan skor nilai tertinggi 30 dan terendah 13. Dari nilai yang diperoleh rata-rata Mean berkisar $=23,51$, Nilai tengah $=62,9$ serta frekuensi kelompok Modus $=23,75$ dan nilai $=3,93$ adalah Standar Deviasi. Dengan ini disajikan ke dalam bentuk kurva polygon pada gambar 1 dibawah ini.

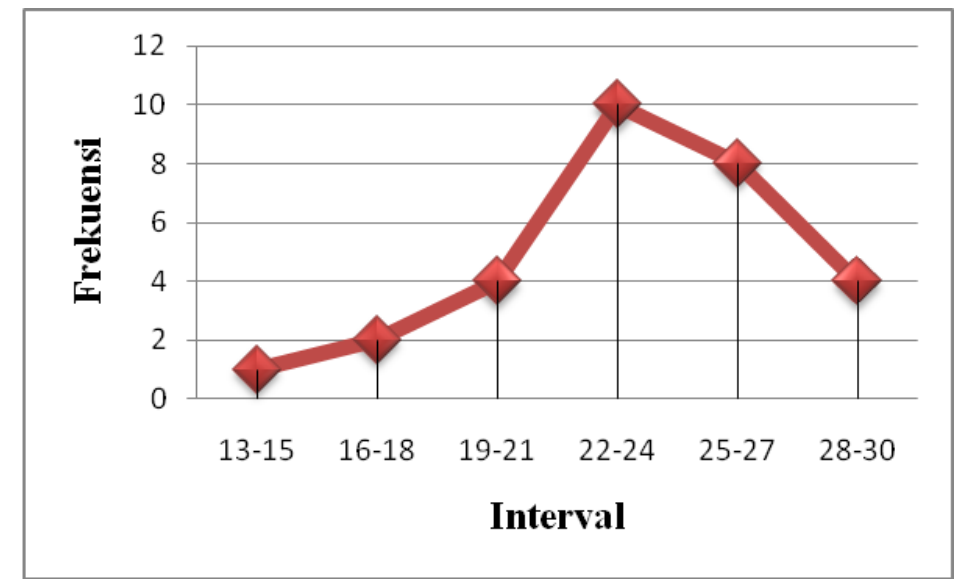

\section{Gambar 01. Data Hasil Post-test Kelompok Eksperimen}

kurva juling negatif yang ditunjukkan pada Gambar 01, diartikan bahwa sebagian besar hasil literasi sain siswa cenderung tinggi.

Berbeda dengan hasil frekuensi literasi sain siswa kelas kontrol yang berjumlah 29 orang dengan skor nilai teratas 25 dan terbawah 8. Dari skor rata-rata yang diperoleh maka Mean berkisar $=15,75$, Median $=55,2$, Modus $=15,37$, Varians $=85,25$, dan Standar Deviasi $=4,30$. Dengan ini disajikan ke dalam bentuk kurva polygon pada gambar 02 dibawah ini.

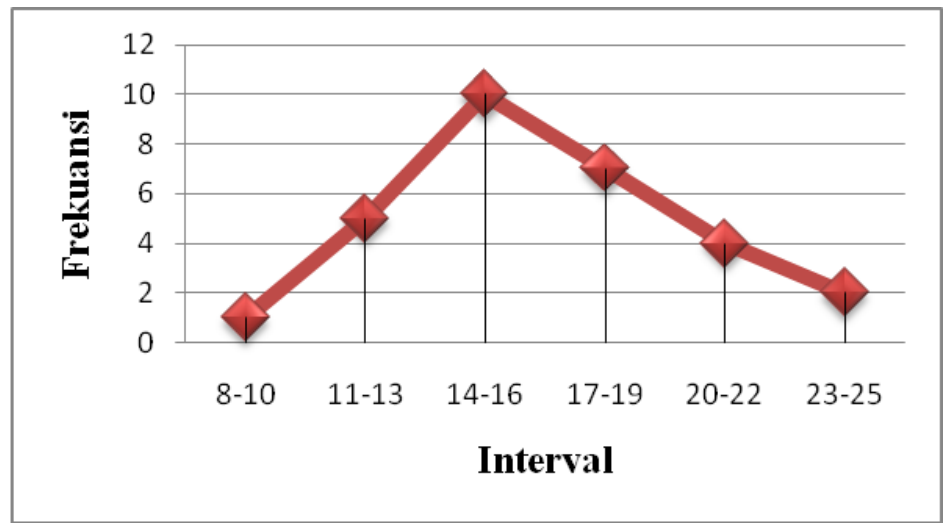

Gambar 02. Data Hasil Siswa Kelompok Kontrol

Kurva polygon gambar 02, tampak terlihat bahwa kurva berbentuk juling positif. Hal ini diartikan sebagian besar hasil berpikir kritis siswa cenderung Sedang.

Hasil Analisis statistik deskriptif selanjutnya dilakukan uji prasyarat dalam hipotesis. Uji normalitas sebaran data serta uji homogenitas varians. Data uji hasil sebaran normalitas literasi sains siswa kelas eksperimen menunjukkan hasil Chi-Square ( $\left.\mathrm{x}^{2}{ }_{\text {hitung }}\right)$ dan tabel $\left(\mathrm{x}^{2}\right.$ tabel) yaitu $1,700<3,182$ dengan tingkat signifikansi $5 \%$ sehingga hasil post-test kelas eksperimen berdistribusi normal. Untuk Chi-Kuadrat kelas kontrol ( $\left.{ }^{2}{ }_{\text {hitung }}\right)$ dan tabel $\left(\mathrm{x}^{2}\right.$ tabel $)$ 
yaitu $1,805<3,187$ dengan tingkat signifikansi $5 \%$ sehingga data hasil siswa kelas kontrol berdistribusi normal. Maka disimpulkan bahwa data hasil post-test pada kedua kelas terbukti dari data distribusi normal maka dilanjutkan dengan uji homogenitas.

Uji homogenitas varians dengan dua kelas menunjukkan nilai $\mathrm{F}_{\text {tabel }}$ (dengan tingkat signifikansi $5 \%)<F_{\text {hitung }}(1,07<1,88)$, sehingga diartikan bahwa varians data kedua kelas tersebut homogen. Setelah uji prasyarat, maka dilanjutkan ke uji hipotesis.

Hasil analisis uji-t dengan rumus polled varians memperoleh $t_{\text {hitung }}$ sebesar 4,30 $t_{\text {tabel }}$ dengan $\mathrm{db}=56$ dengan tingkat signifikan $5 \%$ yaitu 2,00. Hasil perhitungan menunjukkan bahwa $t_{\text {hitung }}>t_{\text {tabel }}(4,30>2,00)$ hal ini $\mathrm{H}_{0}$ ditolak dan $\mathrm{H}_{1}$ diterima. Disimpulkan bahwa siswa yang diajarkan dengan model pembelajaran $P B L$ dengan siswa yang tidak diajarkan model $P B L$ terdapat perbedaan yang signifikan.

\section{Pembahasan}

Dari analisis data yang dihasilkan, model $P B L$ memperoleh hasil meningkat dibandingkan pembelajaran ekspositori. Adanya perbedaan kedua model tersebut diartikan bahwa model $P B L$ berpengaruh besar terhadap literasi sain siswa. Hasil temuan perbedaan pencapaian literasi sains tersebut dapat dijelaskan penyebabnya dari sudut pandang secara teoritik antara model $P B L$ dan ekspositori dimana keduanya memiliki karakteristik yang berbeda dilihat dari defenisi pengertiannya model pembelajaran berbasis masalah adalah suatu pendekatan pembelajaran yang mengangkat masalah dari dunia nyata sebagai suatu hubungan bagi siswa untuk belajar tentang bagaimana cara dalam menyelesaikan masalah dan berpikir kritis, serta untuk memperoleh konsep pengetahuan yang mendasar dari materi pembelajaran (Muspita dkk 2013).Sesuai dengan langkah model PBL yaitu pada tahap Pertama dalam proses pembelajaran siswa dihadapkan dengan sebuah masalah, dimana masalah tersebut sesuai yang terjadi di dalam kehidupan nyata siswa contoh masalah yang berhubungan dengan kegiatan sekolah maupun kegiatan diluar sekolah berdasarkan kenyataan yang temui dalam kehidupannya. Dengan keadaan dunia nyata maka akan melatih siswa untuk merancang menyelesaikan permasalahan. Hal ini siswa akan mengembangkan keterampilan literasi sainsnya. Sejalan dengan pendapat (Novita, dkk 2014) menyatakan bahwa langkah awal dari pembelajaran berbasis masalah yaitu menyampaikan masalah, dengan adanya masalah akan menemukan konsep dari sebuah permasalahan tersebut. Langkah Kedua, yaitu mengarahkan siswa untuk belajar. Pada langkah ini siswa diberi kesempatan untuk mencari informasi dan memberikan ide-ide untuk pemecahan masalah secara individual maupun kelompok. Pada tahap Ketiga disini guru hanya sebagai fasilitator dan media dalam kegiatan menyelesaikan masalah siswa dimotivasi untuk mencari sendiri solusi dan jawaban mengenai masalah tersebut serta terlatih untuk bertanggung jawab dalam berpartisipasi dalam tim. Pada tahap Keempat siswa mengembangkan dan membuat sebuah laporan, dan tahap Kelima mengevaluasi kembali proses penyelesaian masalah.

Hal tersebut sangatlah berbeda dengan model pembelajaran ekspositori, dimana dalam kelas ekspositori pembelajaran hanya menekankan pada proses penyampaian materi saja dari seorang guru kepada sekelompok siswa, hal ini dimaksudkan agar siswa bisa menguasai materi secara menyeluruh. Kemudian dari langkah pembelajaran terdiri dari empat tahap dimana tahap Pertama yaitu tahap persiapan, siswa mempersiapkan untuk menerima materi pembelajaran, setelah itu guru menyediakan materi pembelajaran jelas dan sistematis. Kemudian tahap Kedua guru mulai menguaraikan secara singkat tentang materi pembelajaran dan memberikan pertanyaan kepada siswa. Pada tahap Ketiga guru mulai menghubungkan materi pembelajaran dengan pengalaman siswa yang terjadi dalam kehidupannya, agar siswa bisa memahami keterkaitan struktur materi dengan pengetahuan yang sudah dimilikinya. Berikut pada tahap Keempat siswa dituntut untuk memahami konsep dari materi yang telah di sajikan dan pada langkah terakhir guru melakukan evaluasi kepada siswa terhadap pemahaman materi yang mereka pelajari. 
Pada dasarnya pembelajaran yang membuat siswa menjadi aktif sangat mendukung untuk meningkatkan kemampuan berpikir dan berkomunikasi secara terstruktur. Berdasarkan pembahasan diatas maka sangat jelas perbedaannya bahwa $P B L$ perlu diterapkan dalam suatu proses pembelajaran dikarenakan $P B L$ dapat mengaktifkan siswa dalam proses kegiatan pembelajaran dan mampu meningkatkan cara berpikir siswa sehingga literasi sains siswa akan terbentuk dengan sendirinya dalam proses pembelajaran berlangsung.

Penelitian lain yang senada dengan hasil penelitian ini (Aiman, dkk 2019) Pengaruh Model Pembelajaran Berbasis Masalah Terhadap Literasi Sains Dan Berpikir Kritis Siswa Sekolah Dasar . Dalam hasil penelitian tersebut menunjukkan bahwa pembelajaran dengan model pembelajaran berbasis masalah berpengaruh tinggi terhadap peningkatan literasi sains dalam pembelajaran IPA.

\section{KESIMPULAN}

Dari hasil uji hipotesis serta pembahasaan, disimpulkan terdapat perbedaan hasil yang signifikan antara literas sains kelompok peserta didik yang diajarkan menggunakan model $P B L$ dan kelompok siswa dengan metode ekspositori pada mata pelajaran di sekolah dasar Muhammadiyah 2 Kota Kupang. Hasil dapat dilihat pada rerata skor literasi sains siswa yang menggunakan $P B L$ sebesar 23,51 untuk rerata menggunakan metode ekspositori sebesar15, 75. Oleh karena itu hasil literasi sains dalam pembelajaran $P B L$ lebih baik jika dibandingkan metode ekspositori..

\section{DAFTAR PUSTAKA}

Aiman, U., Dantes, N., \& Suma, K. (2019). Pengaruh model pembelajaran berbasis masalah terhadap literasi sains dan berpikir kritis siswa sekolah dasar. Jurnal Ilmiah Pendidikan Citra Bakti, 6(2), 196-209.

Hidayati, F., Juliato. 2018. Penerapan Literasi Sains dalam Pembelajaran IPA di Sekolah Dasar untuk Meningkatkan Kemampuan Berpikir Kritis Siswa dalam Memecahkan Masalah. Seminar Nasional Pendidikan. Banjarmasin 24 Maret 2018. ISBN 978-602-6483-63-8.

Muspita, Z., I.Wayan. L., Sariyasa. 2013. "Pengaruh Model Pembelajaran Berbasis Masalah Terhadap Kemampuan Berfikir Kritis, Motivasi Belajar, dan Hasil Belajar IPS Siswa Kelas VII SMPN 1 Aikmel”. e-Journal Program Pascasarjana Universitas Pendidikan Ganesha. Program Studi Pendidikan Dasar (Volume 3 Tahun 2013)

Rahayuni, G. 2016. "Hubungan Keterampilan Berpikir Kritis Dan Literasi Sains Pada Pembelajaran Ipa Terpadu Dengan Model PBM Dan STM”. Jurnal Penelitian dan Pembelajaran IPA.JPPI, Vol. 2, No. 2. Hal. 131-146 e-ISSN 2477-2038 131.

Triyana, I. Y., I.B. Surya Manuaba, Md, Putra. 2014. Pengaruh Model Pembelajaran Berbasis Masalah (PBM) Terhadap Hasil Belajar IPA Siswa Kelas V SD Gugus Iv Tampaksiring Tahun Pelajaran 2013/2014. Jurnal Mimbar PGSD Universitas Pendidikan Ganesha Jurusan PGSD (Vol: 2 No: 1

Windyariani, S. 2017. Kemampuan Literasi Sains Siswa SD Pada Konteks Melestarikan Capung. Jurnal Pendidikan Biologi (BIOSFERJPB). Volume 10 No 1,17-21. ISSN 0853-2451.

Yuriza, P. E., Adisyahputra., Diana V. Sigit. dkk. 2018.“Hubungan Antara Kemampuan Berpikir Tingkat Tinggi dan Tingkat Kecerdasan dengan Kemampuan Literasi Sains Pada Siswa SMP”. Jurnal Pendidikan Biologi (biosferjpb). Tahun 2018, Volume 11 No 1. 13-20 E-ISSN: 2614-3984.

Zainab., Mustika W., Sarah M. 2017. "Pengembangan Instrumen Kognitif Literasi Sains Pada Pokok Bahasan Tekanan Di Kelas VIII Smp Kota Banjarmasin”. Jurnal Ilmiah Pendidikan Fisika. Vol 1 No. 3 Oktober 2017. 